\title{
Clonidine-induced body temperature changes in rats with anterior or posterior cortical damage
}

\author{
ROBERT L. ISAACSON, BRANDON YONGUE, and RICK CARRERA \\ University of Florida, Gainesville, Florida 32611
}

\begin{abstract}
Animals with anterior or posterior neocortical lesions as well as intact control animals were evaluated for changes in $\alpha$-adrenergic sensitivity at five postoperative times. Colonic temperature decreases were measured in response to clonidine at each of the postoperative periods. The result indicated that a heightened heat-loss response was induced by clonidine that lasted 21 or more days after destruction of the posterior neocortex. This exaggerated response to the drug was not found in animals with anterior neocortical lesions.
\end{abstract}

In studying the induction of supersensitivity of the norepinephrine (NE) mediated systems, Zis and Fibiger (1975) found that the reduction in colonic temperature produced by clonidine was substantially increased by prior injection of 6-hydroxydopamine into ascending NE systems in the brainstem. Their evidence suggested that destruction of the ventral NE bundle was critical to this effect, which was found both 1 and 3 months postoperatively. These lesions greatly reduced hypothalamic NE levels but did not affect NE levels in cortex or hippocampus.

The effects of central application of NE in regard to body temperature seem to be the result of its $\alpha$-adrenergic actions in many species, including the mouse (Brittain \& Handley, 1967), cats (Burks, 1972), and rabbits (Dhawan \& Dua, 1971). Further support for the importance of $\alpha$-adrenergic stimulation on the reduction of body temperature comes from studies in which the temperature loss produced by interventricular administration of NE could be blocked by $\alpha$ - but not by $\beta$-antagonists (Cantor \& Satinoff, 1976).

Clonidine is considered to be a stimulator of $\alpha$ adrenergic receptors (Anden, Corrodi, Fuxe, Hokfelt, Hokfelt, Rydin, \& Svensson, 1970). Supporting this view, it acts in a negative feedback fashion to regulate the release of noradrenaline from both peripheral and central neurons (Cubeddu, Barnes, Langer, \& Weiner, 1974; Haggendal, 1973; Hedqvist, 1974; Kirpekar, Furchgott, Wakade, \& Prat, 1973; Starke \& Montel, 1973, 1974; Stjarne, 1975). Administration of the drug by intracranial or intraperitoneal routes reduces colonic temperature (Taylor \& Laverty, 1969; Tsoucaris-Kupfer \& Schmitt, 1972). The hypo-

This research was supported, in part, by NIH Grant RR 07-021-11 to the University of Florida and by NIH 5 T 01 MH-10320-12 to the Center for the Neurobiological Sciences, University of Florida. Requests for reprints should be sent to Professor Robert L. Isaacson, Department of Psychology, University of Florida, Gainesville, Florida 32611. thermic response to clonidine administration can be eliminated by treatment with phenoxybenzamine, and $\alpha$-adrenergic antagonist (Reid, Lewis, \& Meyers, 1975 ) but not by propranalol, a $\beta$-adrenergic antagonist (Fukushima \& Itoh, 1975).

The effect of the $\alpha$-adrenergic agonist clonidine is independent of ambient temperature, producing hypothermic responses of similar magnitude at both $6^{\circ}$ and $20^{\circ} \mathrm{C}$.

Several forms of brain damage have been shown to produce progressive alterations in behavior and in reactions to pharmacologic agents. This has been shown after damage to the hippocampus (Lanier \& Isaacson, 1975; Lanier, Petit, \& Isaacson, 1974) and other brain areas (e.g., Campbell, Ballantine, \& Lynch, 1971; Glick \& Marsanico, 1974; Miczek \& Grossman, 1972; Miczek, Kelsey, \& Grossman, 1972; Pompi, 1974).

Neocortical lesions produce differences in the incorporation of $\left[{ }^{3} \mathrm{H}\right]$ uridine at long and short postoperative periods (Wells, 1976), and other progressive changes in behavior after neocortical damage can be found in other studies (e.g., Lanier et al., 1974). Furthermore, differential sensitivity to receptor stimulating drugs can be found after lesions in different cortical regions of the rat neocortical surface. For example, Glick and Cox (1976) found enhanced sensitivity to apomorphine after frontal lesions, but not to clonidine. The frontal cortex of the rat seems to receive a relatively dense DA input, especially to the deeper cortical layers (Bunney \& Agahajanian, 1976). In general, there is a widespread distribution of NE innervation of the rat neocortex (Dahlstrom \& Fuxe, 1964; Ungerstedt, 1971), although there may be a preferential distribution of NE from locus coeruleus to the posterior neocortex. There is a greater decrease of NE in posterior than in anterior areas after lesions of the locus coeruleus (Worth, Collins, Kett, \& Austin, 1976). 
The present research represents an initial effort to determine the time course of possible differential adrenergic responsivity of rats to lesions of the anterior and posterior neocortical surface. The reduction of colonic temperature by clonidine was used as the measure of responsiveness. This adrenergic agonist was chosen because of its selective activation of $\alpha$-receptors and to make the study comparable to that of $\mathrm{Zis}$ and Fibiger (1975), who studied changed adrenergic sensitivity induced by other methods with this drug.

\section{METHOD}

The subjects were male hooded rats of the Long-Evans strain, housed in individual cages. The room was maintained on a 12-h/ 12-h light-dark schedule. Food and water was available ad lib.

All operated animals were anesthetized with pentobarbital. Under clean surgical procedures, the scalp was opened and holes trephined over anterior or posterior neocortical regions. The dura was opened and small lesions were made by aspiration under visual guidance. In most animals, the skull openings and lesions were made bilaterally, although three animals received unilateral lesions. After surgery, the scalp was replaced and sutured. The animals received 60,000 units of Bicillin postoperatively. On completion of the experiment, the animals were sacrified with an overdose of pentobarbital, intracardially perfused with saline followed by Formalin, and the brains removed. Photographs of the dorsal surface were made before processing for histological evaluation. The brains were embedded in celloidin, sectioned, mounted, and stained with thionin for histological evaluation. All animals with signs of superficial meningeal infection or incidental damage to subcortical structures were discarded from the data analysis.

The data from five animals with posterior neocortical damage, four animals with anterior neocortical damage, and seven control animals, are reported. Three of the seven control animals received unilateral neocortical damage but were not behaviorally different from the intact animals and were combined with the results from four other intact control animals. Composite drawings of the bilateral cortical lesions are shown in Figure 1.

The devices used to restrain the animals were constructed of cylindrical Plexiglas approximately $20.5 \mathrm{~cm}$ in length and $7 \mathrm{~cm}$ in diameter. Each cylinder was longitudinally sliced and glued to a flat Plexiglas bottoni of $6 \mathrm{~cm}$ wide. Each cylinder was enclosed at one end by a Plexiglas strip. Several holes were drilled in these strips to allow for ventilation. The opposite ends of the chambers were closed by means of horseshoe-shaped gates which could be adjusted to the length of the animal. A slot in the gate allowed the experimenter to manipulate the rat's tail, which facilitated insertion of the thermometer probe.

All testing was done in the same experimental room at an ambient temperature of $22^{\circ}-23^{\circ} \mathrm{C}$. The rats were allowed to rest in the restraining devices for $10 \mathrm{~min}$ before the initial temperature recording. Rectal temperature was recorded by inserting the rectal probe of a Yellow Springs Instrument Company Model 73 TeleThermometer, $5 \mathrm{~cm}$ into the rectum. The probe was cleaned after each use with alcohol and coated with petroleum jelly before insertion. Four days before surgery, the animals were restrained and injected with $1.0 \mathrm{ml} / \mathrm{kg}$ physiological saline. Ten minutes after being placed in the restraining chamber, their mean initial temperatures were $37.83^{\circ} \mathrm{C}$. The injection of saline produced an increase of $0.18^{\circ} \mathrm{C}(\mathrm{SEM}=.06) 75 \mathrm{~min}$ afterwards. The next day, 3 days before surgery, the animals were injected with $0.1 \mathrm{mg} / \mathrm{kg}$ clonidine, following the same procedure. This produced a mean decrease of $2.62^{\circ} \mathrm{C}$ (SEM $=0.17$ ) in the temperature of the animals. The postinjection time of the maximal decrease was
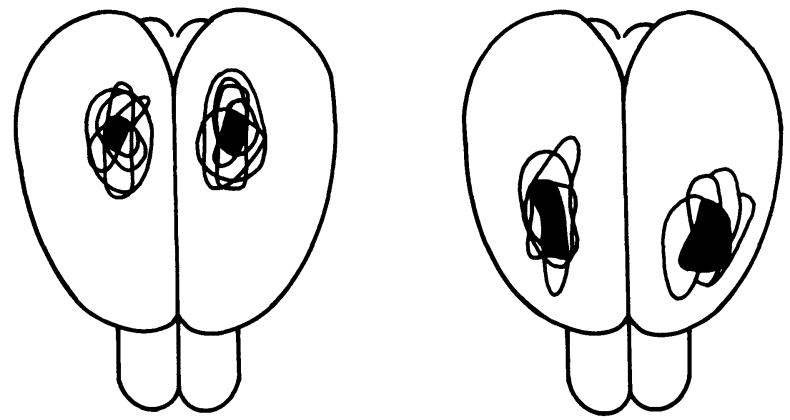

Figure 1. Drawings of lesions of the neocortical damage in the anterior (left) and posterior lesion groups. Drawings made on the basis of photographic analysis of brain surfaces and subsequent histological confirmation of lesion extent.

$75 \mathrm{~min}$. The decrease in temperature found before surgery after the first injection of clonidine was greater than found in control animals during postoperative testing. This may have been due to the animals' greater struggling to escape from the apparatus during the initial testing sessions, or it may be due to a lasting change in responsiveness to clonidine following this first administration.

In testing after surgery, $10 \mathrm{~min}$ after an initial temperature recording in the apparatus, each animal was injected IP with $0.10 \mathrm{mg} / \mathrm{kg}$ clonidine through a slot in the floor of the chamber. Subsequent temperature recordings began $15 \mathrm{~min}$ after. the injection, and were repeated at 15-min intervals for a duration of $120 \mathrm{~min}$. This procedure was repeated for all groups at $4,7,14$, 21 , and 28 days after surgery.

\section{RESULTS}

The postoperative baseline temperatures recorded before injection did not differ among the groups or differ from those recorded in the same manner 3 days preoperatively. The extremes of temperatures recorded before the drug was given on the 4 th postoperative day ranged from $37.37^{\circ}$ to $38.0^{\circ} \mathrm{C}$. No systematic changes in baseline occurred over the 5 postoperative test days in any of the groups.

The data were analyzed on the basis of decreases in colonic temperature produced by the clonidine for each animal. The median maximal decreases for each group are shown in Figure 2.

The times after injection at which the greatest temperature reductions occurred became longer after the injection for all groups except the animals with anterior neocortical damage. For example, on Postoperative Day 4, the median maximal decrease occurred at $1 \mathrm{~h}$ for both animals with posterior cortical damage and the control subjects. On Postoperative Day 28, the maximal decreases occurred $1.5 \mathrm{~h}$ after injection for both groups. Evaluation of these changes by a sign test showed the changes to be significant $(p<.025)$. The anterior lesion group, on the other hand, showed a delayed maximal response to clonidine (median: $1.5 \mathrm{~h}$ ) which remained the same through the course of testing.

To determine if changes in the maximal tempera- 


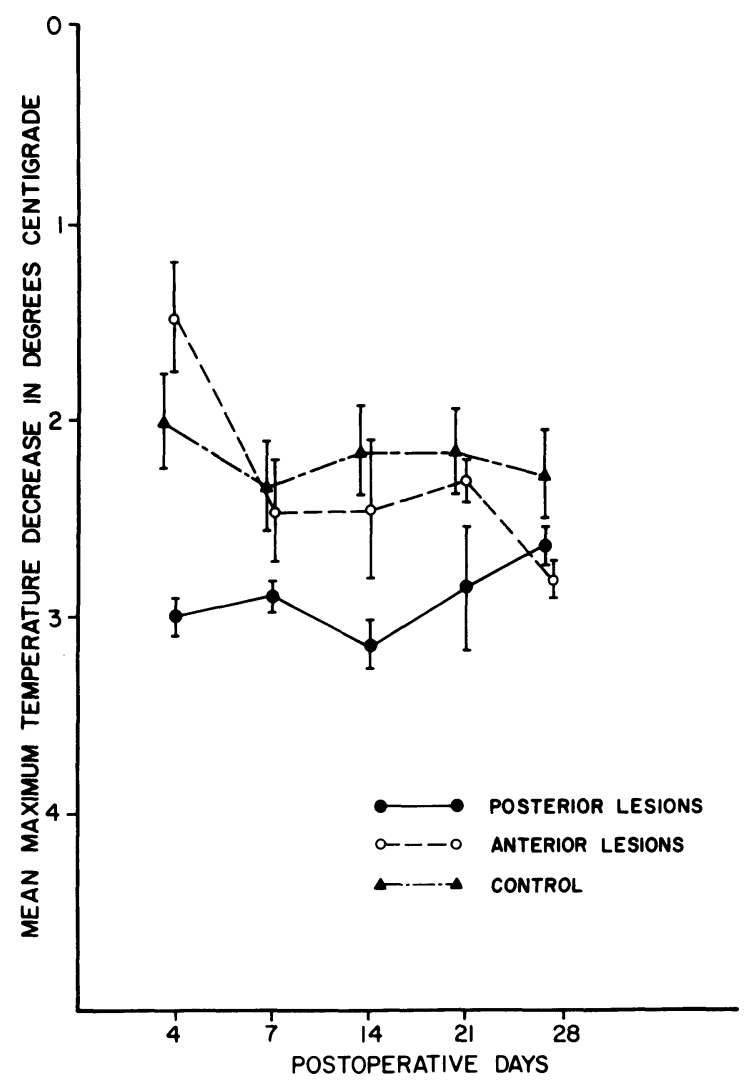

Figure 2. Mean maximal temperature decreases after clonidine for animals with anterior and posterior neocortical lesions and control animals. Vertical bars at each mean indicate $\mathrm{SE}$ of group scores.

ture decreases occurred across testing periods, Friedman analyses were made for all groups. The only group for which a significant change across postoperative periods was found was the group with anterior cortical lesions $(p<.05)$. As can be seen in Figure 2, this was due to a depression in the clonidine-induced reaction when tested 4 days after surgery. A Friedman test made on this group for the last four postoperative periods was not significant. All animals in this group had temperature reductions comparable to those of the control group on Postoperative Days 7-28.

To evaluate the enhanced temperature drop found in the animals with posterior cortical lesions, comparisons were made between the posterior lesion and control groups. Since the Friedman test failed to show changes over testing days for these groups, a Mann-Whitney $U$ test was performed between the mean decreases from all testing days for the two groups. The results indicated a significant decrease in temperature for the posterior lesion group relative to the control subjects $(\mathrm{p}<.01)$.

From the data presented in Figure 2, it appears that there is a convergence in the mean temperature decreases between the posterior lesion group and the controls on Postoperative Day 28, but with the absence of a significant change, as indicated by the Friedman test, the conclusion of a convergence must be considered tentatively.

\section{DISCUSSION}

The data obtained in the present study indicate an enhanced sensitivity to clonidine, as measured by a decrease in body temperature after the drug, which lasts at least 3 weeks after surgery and possibly longer. The present data do not allow a firm conclusion that the hypersensitivity found in the posterior lesion group has dissipated by 28 days. The group of animals that received anterior lesions did not show an enhanced reaction to clonidine and, indeed, were hyposensitive to the drug 4 days after surgery. On subsequent postoperative testing days, they were indistinguishable from control animals. Further, unilateral lesions of the neocortical surface failed to affect clonidine sensitivity.

Following the interpretation of $\mathrm{Zis}$ and Fibiger (1975) of the enhanced responsiveness to clonidine, that is, the induction of supersensitivity in central $\alpha$-adrenergic neurons, our data would suggest that posterior neocortical lesions induce a supersensitivity of NE-sensitive neurons, as well. However, such a conclusion must be tempered by the possibility that the clonidine-induced reaction may be a consequence of changes in other neurotransmitter systems. Clonidine could have produced its effects by stimulation of epinephrine (E) receptors (Bolme, Corrodi, Hokfelt, Lidbrink, \& Goldstein, 1974), changing ACTH or corticosteroid secretion (Ganong, Kramer, Salmon, Reid, Lovinger, Scapagnini, Boryczka, \& Schackelford, 1976; Van Loon, Scapagnini, Cohen, \& Ganong, 1971), by activating histamine H2-receptors (Sastry \& Phyllis, 1977), or by indirect effects on serotonergic (5-HT) systems (Svensson, Bunney, \& Aghajanian, 1975).

The possible return of normal colonic temperature responses to clonidine in the lesioned rats could reflect a plasticity in the catecholamine systems. Both collateral and "compensatory" sprouting have been demonstrated in these systems, at least when neurochemical lesions are made early in life (Devor \& Schneider, 1975; Jonsson, 1976; Jonsson, Pycock, \& Sachs, 1973; Sachs \& Jonsson, 1975; Schneider \& Jhaveri, 1974). After early administration of 6hydroxydopa, a permanent decrease in forebrain $\mathrm{NE}$ is found, but NE increases in the brainstem are also found. This is thought to be due to the accumulation of NE in anomalous axon sprouting in the brainstem (Zieher \& Jaim-Etcheverry, 1973). However, these sprouting changes are not limited to the damage in the infant brain (see Moore, 1975, for review).

The effect of clonidine on DA systems is unlikely to be of importance for the present study, because these effects are found with low ambient tempera- 
tures and not at those used in the present study (Reid et al., 1975; Yehuda \& Wurtman, 1972). However, changes in the DA systems have been reported that may be related to the short-term effects found after frontal cortical damage, an area receiving considerable DA innervation.

The ability of DA-sensitive neurons to develop supersensitivity has been shown in a number of ways. These include denervation (Ungerstedt, 1971) and the administration of agents that block or reduce DA transmission (Gianutsos, Drawbaugh, Hynes, \& Lal, 1974; Tarsy and Baldessarini, 1973; Voigtlander, Losey, \& Triezenberg, 1975; Yarbrough, 1975).

In all likelihood, however, the effect of clonidine on body temperature found in this study is due to its $\alpha$-adrenergic receptor stimulating effects. These involve a decrease in body temperature by means of an enhanced heat-loss mechanism (Fukushima \& Itoh, 1975). Nevertheless, as mentioned above, changes in other neural mechanisms cannot be excluded as causes of the changes found in this study.

\section{REFERENCES}

Anden, N. E., Corrodi, H., Fuxe, K., Hokfelt, B., Hokfelt, T., Rydin, C., \& Svensson, T. Evidence for a central noradrenaline receptor stimulation by clonidine. Life Sciences, 1970, 9, 513-523.

Bolme, P., Corrodi, H., Hokfelt, T., Lidbrink, P., \& Goldstein, M. Possible involvement of central adrenaline neurons in vasomotor and respiratory control. Studies with clonidine and its interactions with piperoxane and yohimbine. European Journal of Pharmacology, 1974, 28, 89-94.

Brittain, R. T., \& Handley, S. L. Temperature changes produced by the injection of catecholamines and 5-hydroxytryptamine into the cerebral ventricles of the conscious mouse. Journal of Physiology (London), 1967, 192, 805-813.

Bunney, B. S., \& Aghajanian, G. K. Dopamine and norepinephrine innervated cells in the rat prefrontal cortex: Pharmacological differentiation using microiontophoretic techniques. Life Sciences, 1976, 19, 1783-1792.

Burkes, T. F. Central alpha adrenergic receptors in thermoregulation. Neuropharmacology, 1972, 11, 615-624.

Campbell, B. A., Ballantine, P., II, \& Lynch, G. Hippocampal control of behavioral arousal and possible interactions with recovery after frontal lesions. Experimental Neurology, 1971, 33, 159-170.

Cantor, A., \& Satinoff, E. Thermoregulatory responses to intraventricular norepinephrine in normal and hypothalamicdamaged rats. Brain Research, 1976, 108, 125-141.

Cubeddu, L. X., Barnes, E., Langer, S. Z., \& Weiner, N. Release of norepinephrine and dopamine-B-hydroxylase by nerve stimulation. I. Role of neuronal and extraneuronal uptake and of alpha presynaptic receptors. Journal of Pharmacology and Experimental Therapeutics, 1974, 190, 431-450.

DAhlstrom, A., \& FUXE, K. Evidence for the existence of monoamine-containing neurons in the central nervous system. I. Demonstration of monoamines in the cell bodies of brain stem neurons. Acta Physiologica Scandinavica, 1964, 62, Suppl. 232, 1-55.

Devor, M., \& Schneider, G. E. Neuroanatomical plasticity: The principles of conservation of total axonal aborization. In F. Vital-Durand \& M. Jennerod (Eds.), Aspects of neural plasticity. Paris: Editions INSERM., 1975.

Dhawan, B. N., \& DuA, P. R. Evidence for the presence of alpha-adrenoceptors in the central thermoregulatory mechanism of rabbits. British Journal of Pharmacology, 1971, 43, 497-503.

Fúushima, N., \& Iтон, S. Role of adrenergic receptors in the central thermoregulatory mechanism of the rat. Japanese Journal of Physiology, 1975, 25, 621-631.

Ganong, W. F., Kramer, N., Salmon, J., Reid, I. A., Lovinger, R., SCAPAGnini, U., BoryczKa, A. T., \& SHACKELFORD, R. Pharmacological evidence for inhibition of ACTH secretion by a central adrenergic system in the dog. Neuroscience, 1976, 1, 167-174.

Gianutsos, G., Drawbaugh, R. B., Hynes, M. D., \& Lal, H. Behavioral evidence for dopaminergic supersensitivity after chronic haloperidol. Life Sciences, 1974, 14, 887-898.

Glick, S. D., \& Cox, R. D. Differential sensitivity to apomorphine and clonidine following frontal cortical damage in rats. European Journal of Pharmacology, 1976, 36, 241-245.

Glick, S. D., \& Marsanico, R. G. Shifting of the d-amphetamine dose-response curve in rats with frontal cortical ablations. Psychopharmacologia, 1974, 36, 109.

HAGGENDAL, J. Regulation of catecholamine release. In E. Usdin \& S. H. Snyder (Eds.), Frontiers in catecholamine research. New York: Pergamon Press, 1973. Pp. 531-535.

Hedquist, P. Role of the a-receptor in the control of noradrenaline release from sympathetic nerves. Acta Physiologica Scandinavica, 1974, 90, 158-165.

Jonsson, G. Developmental characteristics of central monoamine neurons and their reciprocal relations. Experimental Neurology, 1976, 53, 801-814.

Jonsson, G., Pycock, C., \& SAchs, C. Plastic changes of central noradrenaline neurons after 6-hydroxydopamine. In E. Usdin \& S. Snyder (Eds.), Frontiers in catecholamine research. New York: Pergamon Press, 1973.

Kirpekar, S. M., Furchgott, R. F., Wakade, A. R., \& Prat, J. C. Inhibition by sympathomimetic amines of the release of norepinephrine evoked by nerve stimulation in the cat spleen. Journal of Pharmacology and Experimental Therapeutics, 1973, 187, 529-538.

LANiER, L. P., \& IsAacson, R. L. Activity changes related to the location of lesions in the hippocampus. Behavioral Biology, 1975, 13, 59-69.

Lanier, L. P., Petit, T. L., \& Isaacson, R. L. Protection against effects of brain damage by catecholamine depletion is test dependent. Brain Research, 1974, 82, 374-377.

MiczeK, K. A., \& Grossman, S. P. Effects of septal lesions in inter- and intraspecies aggression in rats. Journal of Comparative and Physiological Psychology, 1972, 79, 37-45.

MiczeK, K. A., Kelsey, J. E., \& Grossman, S. P. Time course of effects of seytal lesions on avoidance, response suppression, and reactivity to shock. Journal of Comparative and Physiological Psychology, 1972, 79, 318-327.

Moore, R. Y. Monoamine neurons innervating the hippocampal formation and septum: Organization and response to injury. In R. L. Isaacson \& K. H. Pribram (Eds.), The hippocampus (Vol. 1). New York: Plenum Press, 1975. Pp. 215-238.

PompI, K. F. Immediate effect of septal area damage on DRL performance in the rat. Journal of Comparative and Physiological Psychology, 1974, 86, 523-530.

Reid, J. L., Lewis, P. J., \& Myers, M. G. Role of central dopaminergic mechanisms in piribedil and clonidine induced hypothermia in the rat. Neuropharmacology, 1975, 14, 215-220.

SACHS, C., \& Jonsson, G. 5,7-Dihydroxytryptamine-induced changes in the postnatal development of central 5-hydroxytryptamine neurons. Medical Biology, 1975, 53, 156-164.

SAstry, B. S. R., \& Phyllis, J. W. Evidence that clonidine can activate histamine $\mathrm{H}_{2}$-receptors in rat cerebral cortex. Neuropharmacology, 1977, 16, 223-225.

SCHNEIDER, G. E., \& JHAVERI, S. R. Neuroanatomical correlates of spared or altered function after brain lesions in the newborn hamster. In D. G. Stein, J. J. Rosen, \& N. Butters (Eds.), 
Plasticity and recovery of function in the central nervous system. New York: Academic Press, 1974. Pp. 65-110.

StARKe, K., \& Montel, H. Alpha-receptor modulation of transmitter release from central noradrenergic neurons. NaunynSchmiedeberg's Archives of Pharmacology, 1973, 279, 53-60.

STARKE, K., \& Montel, H. Influence of drugs with affinity for alpha-adrenoceptors on noradrenaline release by potassium, tyramine, and dimethylphenylpiperazinium. European Journal of Pharmacology, 1974, 27, 273-280.

STJARNE, L. Selectivity for catecholamines of presynaptic alpha receptors involved in feedback control of sympathetic neurotransmitter secretion in guinea-pig vas deferens. NaunynSchmiedeberg's Archives of Pharmacology, 1975, 288, 295-303.

Svensson, T. H., Bunney, B. S., \& Aghajanian, G. K. Inhibition of both noradrenergic and serotonergic neurons in brain by the $a$-adrenergic agonist clonidine. Brain Research, 1975, 92, 291-306.

TARsy, D., \& Baldessarini, R. Pharmacologically induced behavioral supersensitivity to apomorphine. Nature New Biology, 1973, 245, 262-263.

TAYlOR, K. M., \& LAVERTy, R. The metabolism of tritiated dopamine in regions of the rat brain in vivo. Journal of Neurochemistry, 1969, 16, 1361-1366.

TsOUCARIS-Kupfer, D., \& SCHMitT, H. Hypothermic effect of a-sympathomimetic agents and their antagonism by adrenergic and cholinergic blocking drugs. Neuropharmacology, 1972, 11, 625-635.

UNGERSTEDT, U. Stereotaxic mapping of the monoamine pathways in the rat brain. Acta Physiologica Scandinavica, 1971, Suppl., 367, 1-48.

Van Loon, G. R., Scapagnin, U., Cohen, R., \& Ganong,
W. F. The effect of intraventricular administration of adrenergic drugs on the adrenal venous 17-hydroxycorticosteroid response to surgical stress in the dog. Neuroendocrinology, 1971, 8, 257-272.

Voigtlander, P. F. Von, Losey, E. G., \& Triezenberg, H. J. Increased sensitivity to dopaminergic agents after chronic neuroleptic treatment. Journal of Pharmacology and Experimental Therapeutics, 1975, 193, 88-94.

WELLS, J. Short-term and long-term alterations in the uptake of [ $\left.{ }^{3} \mathrm{H}\right]$-uridine induced by frontal cortex lesions. Brain Research, 1976, 109, 407-412.

Worth, W. S., Collins, J., Kett, D., \& Austin, J. H. Serial changes in norepinephrine and dopamine in rat brain after locus coeruleus lesions. Brain Research, 1976, 106, 198-203.

YARBROUGH, G. G. Supersensitivity of caudate neurons after repeated administration of haloperidol. European Journal of Pharmacology, 1975, 31, 367-369.

YehUDA, S., \& WuRTMAN, R. J. Release of brain dopamine as the probable mechanism for the hypothermic effect of d-amphetamine. Nature, 1972, 240, 477-478.

ZiEHER, L. M., \& JAIM-ETChEVERRY, G. Regional differences in the long-term effect of neonatal 6-hydroxydopa treatment on rat brain noradrenaline. Brain Research, 1973, 60, 199-207.

Zis, A. P., \& Fibiger, H. C. Functional evidence for postsynaptic supersensitivity of central noradrenergic receptors after denervation. Nature, 1975, 256, 659-661.

(Received for publication October 12, 1977; revision accepted January 31, 1978.) 